\title{
Effect of Exercise on the Apparent Energy Digestibility of Timothy and Alfalfa Hay in Thoroughbred Horses
}

\author{
Ryoji KATSUKI, Yo ASAI* and Hirofumi FUJIKAWA
}

Equine Research Institute, Japan Racing Association, 321-4, Tokami-cho, Utsunomiya, Tochigi 320-0856, Japan

Effect of exercise on apparent energy digestibility of timothy and alfalfa hay were estimated in two-year-old horses. Intensity of the exercise was equal to $80 \%$ heart rate max (180 beats/ min) for 5 min between warm-up and cool-down. Timothy and alfalfa hay intakes in the exercise and rest periods did not differ significantly. The apparent energy digestibility and digestibility energy (DE) of timothy hay in exercised horses were significantly lower than in rested horses but there were no significant differences between exercised and rested horses in the apparent energy digestibility or DE of alfalfa hay. These results suggested that exercise in this study decreased energy digestibility of timothy hay and it seemed that the effect of exercise on the energy digestibility of hay was altered by the composition of hay.

Key words: alfalfa, digestibility, exercise, timothy

When feeding racehorses, it is important to know digestible energy (DE) intake, as they require large amounts of energy to perform various exercises. Many factors affect the digestibility of feed; the individuality of horses, chemical composition of feed, level of intake, processing of feed, and exercise [3]. Some reports have indicated that light exercise (walking or trotting) improves the digestibility of feed $[4,6,10]$, but there have no reports on intense exercise, such as cantering or galloping.

This study was designed to examine the effect of intense exercise on the digestibility of timothy and alfalfa hay, which are typical feed for Thoroughbred horses.

Digestion trial 1: Three two-years-old Thoroughbred horses (two males and one female, average weight 450 $\mathrm{kg}$ ) were used. All the horses were housed in a stall with paper bedding (to prevent the horses from eating litter) and fed timothy hay ad libitum. Water was accessed freely. Both the exercise and rest trials were carried out for 5 days after 7 days periods to adjust to test conditions. There was a 9-day period between the exercise and rest trials.

In the exercise trial, the horses were exercised once a day in the morning on the treadmill for horses (Mustang 2200; Kagra, Switzerland) with heart rates monitored with

This article was submitted April 25, 1997, and was accepted January 13, 1998.

*corresponding author. a Heart Rate Master II (PE-3000, Polar, Finland). The exercise schedule is shown in Fig. 1. The intensity of main work was equal to $80 \%$ of the maximum heart rate (180 beats/min) for five minutes.

In the rest trial, horses were rested in their stalls all day. Representative feed and feces samples were taken once a day during the test periods. Samples were dried, ground, mixed thoroughly and analyzed for acidinsoluble ash (AIA) content [9, 10]. The gross energy of feed and feces was determined with bomb calorimeter. The apparent digestibility of energy of hay was calculated based on the AIA ratios of feed and feces.

Digestion trial 2: Four two-year-old Thoroughbred horses (two males and two females, average weight 440 $\mathrm{kg}$ ) were used. All horses were fed alfalfa hay in an amount equal to $2.75 \%$ of body weight. Other conditions and analysis methods were the same as in digestive trial 1 .

The chemical compositions of the timothy and alfalfa hay used in both trials are shown in Table 1 .

Data were subjected to analysis of student's t-test.

Timothy hay intake was $12.7 \mathrm{~kg} /$ day in exercised horses and $12.6 \mathrm{~kg}$ /day in rested horses, which does not represent a significant difference, but the apparent energy digestibility and DE of timothy hay in exercised horses were significantly lower $(\mathrm{p}<0.01)$ than in rested horses (Table 2), in digestion trial 1. 


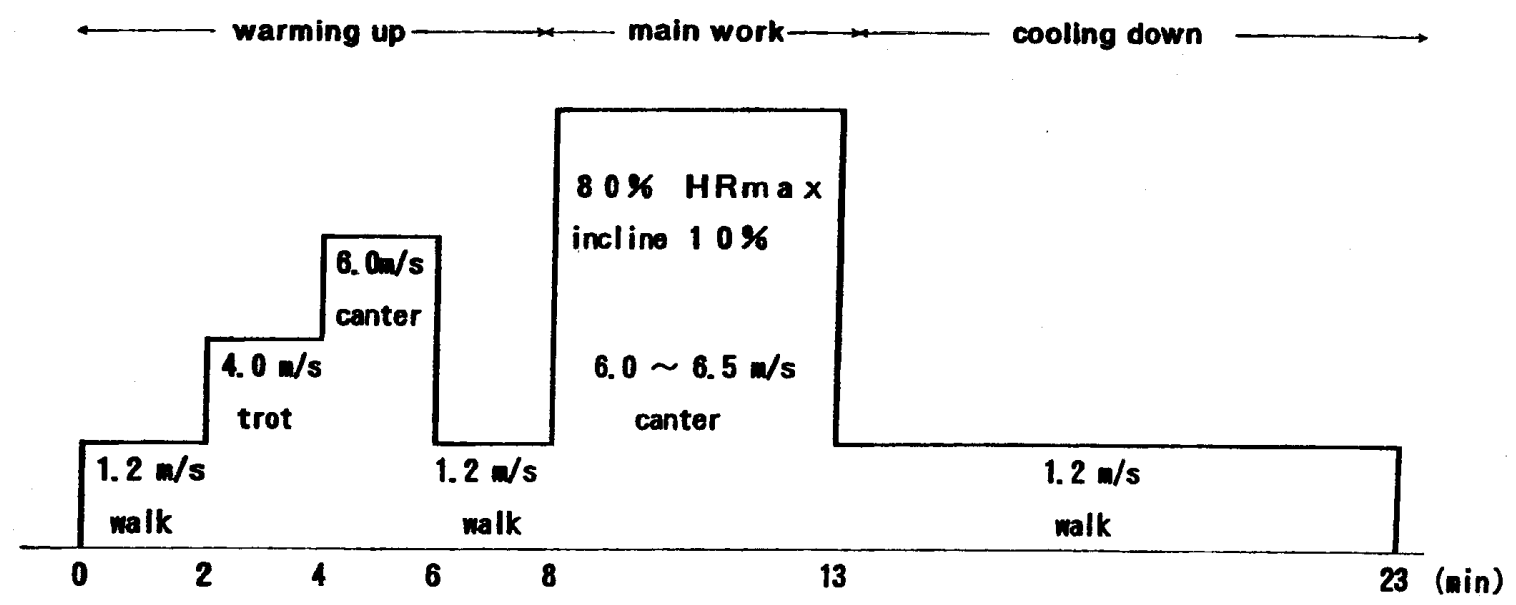

Fig. 1. Exercise menu.

Table 1. Chemical composition of hay used in trials 1 and 2

\begin{tabular}{lcc}
\hline & Timothy (trial 1) & Alfalfa (trial 2) \\
\hline Dry matter $^{1)}$ & $94.5 \%$ & $91.0 \%$ \\
Crude fiber $^{1)}$ & $35.8 \%$ & $27.0 \%$ \\
Crude protein $^{1)}$ & $6.6 \%$ & $19.0 \%$ \\
Crude ash $^{1)}$ & $5.8 \%$ & $8.2 \%$ \\
AIA $^{2}{ }^{2)}$ & $1.60 \%$ & $0.19 \%$ \\
Gross energy $^{2)}$ & $4.32 \mathrm{Mcal} / \mathrm{kg}$ & $4.58 \mathrm{Mcal} / \mathrm{kg}$ \\
\hline
\end{tabular}

※ Acid Insoluble Ash. 1) as fed basis. 2) as dry matter basis.

Table 2. Dry matter intake, digestibility, digestible energy (DE) intake, DE of hays and liveweight gain of the horses exercised and rested

\begin{tabular}{|c|c|c|c|c|c|c|}
\hline & \multicolumn{3}{|c|}{ trial 1 (timothy hay) } & \multicolumn{3}{|c|}{ trial 2 (alfalfa hay) } \\
\hline & exercised & rested & difference $^{1)}$ & exercised & rested & difference $^{1)}$ \\
\hline Hay intake (kg DM/day) & $12.7 \pm 0.2$ & $12.6 \pm 0.7$ & NS & $12.3 \pm 0.4$ & $12.1 \pm 0.5$ & NS \\
\hline Hay intake ( $\mathrm{kg}$ DM/100 kg BW/day) & $2.82 \pm 0.06$ & $2.73 \pm 0.04$ & NS & $2.75^{2)}$ & $2.75^{2)}$ & - \\
\hline Digestibility $(\%)$ & $37.8 \pm 1.7$ & $47.6 \pm 1.1$ & $* *$ & $50.3 \pm 14.5$ & $57.4 \pm 3.2$ & NS \\
\hline DE intake (Mcal/day) & $20.8 \pm 1.1$ & $26.0 \pm 1.1$ & $*$ & $26.6 \pm 7.4$ & $30.1 \pm 2.0$ & NS \\
\hline DE intake (Mcal/100 kg BW/day) & $4.57 \pm 0.21$ & $5.76 \pm 0.09$ & $*$ & $6.00 \pm 1.73$ & $6.84 \pm 0.39$ & NS \\
\hline $\mathrm{DE}$ of hay $(\mathrm{Mcal} / \mathrm{kg} \mathrm{DM})$ & $1.64 \pm 0.07$ & $2.06 \pm 0.05$ & $* *$ & $2.31 \pm 0.66$ & $2.63 \pm 0.15$ & NS \\
\hline
\end{tabular}

Values are the mean \pm standard deviation. 1) *: $\mathrm{P}<0.05$, **: $\mathrm{P}<0.01$. 2) limited feeding.

Alfalfa hay intake were $12.3 \mathrm{~kg} /$ day in exercised horses and $12.1 \mathrm{~kg}$ /day in rested horses (both representing 2.75\% of body weight), and all the alfalfa hay supplied was eaten by the horses. The apparent energy digestibility and DE of alfalfa hay were not significant difference between in exercised and in rested horses (Table 2), in digestion trial 2.

Hay intake in this study was within the limits (3\% of body weight) recommended by NRC (1989) [5]. As reported in a study on donkeys [8], exercise did not have an effect on hay intake. Table 3 shows that light exercise improves the digestibility of feed $[2,4,6-8,10]$. Our result of digestion trial 1 differed from those in these reports, possibly due to differences in diet or the intensity or amount of exercise. Orton (1985b) found that exercise reduced the mean retention time (MRT) of the particles, but increased the MRT of fluid in horses [7]. It was reported that a decreased MRT resulted in less time for enzymic and microbial digestion of carbohydrates, and this effect was much more remarkable with high fiber diets [7]. On the other hand, intense exercise caused a decrease of the digestibility of the diet by the digestive 
Table 3. Reports on the effect of exercise on the apparent digestibility

\begin{tabular}{lcc}
\hline \multicolumn{1}{c}{ Reference } & $\begin{array}{c}\text { Effect of exercise } \\
\text { (digestibility in resting =100) }\end{array}$ & Type of exercise \\
\hline Grandeau (1888) & 106 & walk \\
& 98 & trot \\
Hintz (1982) & 106 & trot \\
Orton (1985a, b) & 119 & trot \\
Worth (1987) & 107 & walk, trot, canter, gallop \\
Pearson (1991)* & 100 & trot \\
This study & 79 & canter \\
This study & 88 & canter \\
\hline
\end{tabular}

*: Animals were donkeys.

tract motion or a decrease of the blood flow in the digestive tract [1]. The intake of a high fiber diet seemed to decrease the energy digestibility of timothy hay by exercise in this study.

In summary, these results suggested that exercise in this study decreased energy digestibility of timothy hay and it seemed that the effect of exercise on the energy digestibility of hay was altered by the composition of hay. Thus, exercised horses should be fed with attention given to both energy supply and feed composition. Further studies will be required on the specific effects that feed composition and exercise levels have on the digestibility.

\section{References}

1. Brouns, F. and Becker, E. 1993. Is the gut an athletic organ? Digestion, absorption and exercise. Sports Medicine. 15: 242-257.

2. Grandeau, L. and Leclerc, A. 1888. Alimentation du cheval de tract. Ann. Sci. Argonom. Paris. 5: 211.

3. Hintz, H.F. 1975. Digestive physiology of the horse. J. South Afr. Vet. Ass. 46: 13-16.

4. Hintz, H.F. 1982. Effect of exercise on digestibility. Eq. Prac. 10: 5-6.

5. National Research Council. 1989. Nutrient
Requirements of Horses. 5th. ed. National Academy of Science, Washington, D.C. 48.

6. Orton, R.K., Hume, I.D. and Leng, R.A. 1985a. Effects of level of dietary protein and exercise on growth rates of horses. Eq. Vet.J. 17: 381-385.

7. Orton, R.K., Hume, I.D. and Leng, R.A. 1985b. Effects of exercise and level of digestive function in horses. Eq. Vet.J. 17: 386-390.

8. Pearson, R.A. and Merritt, J.B. 1991. Intake, digestion and gastrointestinal transit time in resting donkeys given ad libitum hay and straw diets. Eq. Vet.J. 23: 339-343.

9. Vogtmann, H., Pfirter, H.P. and Prabucki, A.L. 1975. A new method of determining metabolisability of energy and digestibility of fatty acid in broiler diets. Br. Poult. Sci. 16: 531-534.

10. Sutton, E.I., Bowland, J.P. and McCarthy, J.F. 1977. Studies with horses comparing $4 \mathrm{~N}-\mathrm{HCl}$ insoluble ash as an index material with total fecal collection in the determination of apparent digestibilities. Can. J. Anim. Sci. 57: 543-549.

11. Worth, M.J., Fontenot, J.P. and Meacham, T.N. 1987. Physiological effects of exercise and diets on metabolism in the equine. Proc. 10th. Eq. Physiol. Sympo. 145-151. 